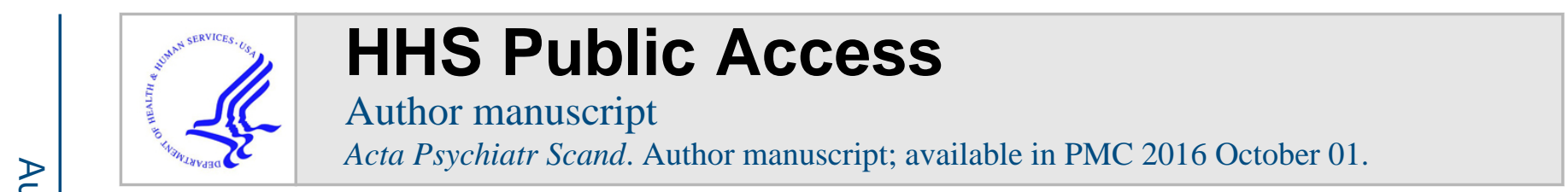

Published in final edited form as:

Acta Psychiatr Scand. 2015 October ; 132(4): 317-318. doi:10.1111/acps.12435.

\title{
The physician-scientist workforce in the United States
}

\author{
Kristina M. Deligiannidis, M.D. \\ Assistant Professor of Psychiatry and Obstetrics \& Gynecology, Director, Depression Specialty \\ Clinic, Women's Mental Health Program, Center for Psychopharmacologic Research and \\ Treatment, University of Massachusetts Medical School, Worcester, MA, USA
}

Kristina M. Deligiannidis: kristina.deligiannidis@umassmemorial.org

\begin{abstract}
Drs. Ågren and Wetterberg conclude in their Letter to the Editor that "the declining proportion of research trained medical doctors in psychiatry is an increasing problem in Sweden." This is concerning since physicians bring to their research the vital experience of caring for patients. This clinical "lens" enormously impacts how physician-scientists make hypotheses and design clinical research either on their own or, increasingly, in collaboration with PhD scientists. The focus of their clinical and translational research is for the benefit of the patient. Unfortunately, over the past 30 years, the number of physicians primarily engaged in research in the United States (US) has declined as the number of physicians engaged in patient care has steadily increased (1). As early as 1979, eminent physician scientists (2) and more recently in the 1990s, national organizations including the Institute of Medicine (3), the Association of American Medical Colleges (AAMC) (4) and the National Institutes of Health (NIH)(5) described challenges for the physician-scientist workforce, including barriers to attracting and retaining clinical investigators in research.

Recommendations from these organizations to increase clinical research training in the US were enacted in the late 1990s at a time when the NIH annual budget doubled from $\$ 13.675$ billion (1998) to $\$ 27.167$ billion (2003). That period saw substantial growth in the number and types of clinical research training programs(6), many pioneered and heavily supported by the NIH itself alongside initiatives by foundations and other non-profit organizations which vitally support medical research.
\end{abstract}

The research funding climate in the US is unfortunately quite different today. Recent economic conditions and other pressures in the US resulted in reduced research funding appropriated to the NIH. The National Institute of Mental Health (NIMH), the seventh largest of the 27 Institutes and Centers which make up the NIH, is the world's largest funding agency for research on mental disorders: its budget accounts for approximately 5\% of the total NIH budget appropriated by Congress annually(7). After adjusting for inflation, the 2015 NIMH budget of $\$ 1.4$ billion is similar to that of 1999 in terms of purchasing power(7) which has translated into only one out of five grant applications being funded. At a time of reduced purchasing power from government agencies, funding from other essential

Declaration of interest

The views expressed in this work are those of the author and do not necessarily reflect the position of the NIH or Acta Psychiatrica Scandinavica. 
research entities including pharmaceutical companies, foundations and other non-profit organizations also contracted.

Given the restrictive funding climate for clinical research in the US, what does the physician-scientist workforce look like? According to data from the American Medical Association (AMA) during 2004-2012, the total number of physicians reporting medical research as their main practice area in 2012 included just 13,717 of the 980,377, or 1.4\% of physicians across medical disciplines; down from $4.6 \%$ in 1985(1). With approximately $2.5 \%$ of all US physicians practicing psychiatry, the percentage who mainly conduct psychiatric research is only a fraction of those 13,717 physicians(8).

The NIH recently completed a rigorous study of the physician-scientist workforce(9) which broadly defined physician-scientists as scientists with professional degrees who hold an MD, $\mathrm{MD}-\mathrm{PhD}$ or are nurse-scientists, dentist-scientists or veterinarian-scientists. Of the 9,000 physician-scientists during 2008-2012 with an NIH Research Project Grant (RPG), 4,192 held an MD and 4,086 held an MD/PhD degree. Growth of new PhD scientists surpassed the near zero growth of physician-scientists, with over 19,000 PhDs holding NIH grants in the same time frame. Not only is the US physician-scientist workforce continuing to decline in terms of numbers and those holding NIH RPGs, but it continues to age, with more established physician-scientists competing more effectively at RPGs than early career physician-scientists (9). Female physician-scientists with either an $\mathrm{MD} / \mathrm{PhD}$ or MD make up approximately 22 and 29\%, respectively, of NIH RPG awardees with a slightly higher percentage receiving funding from the NIMH (33\%) specifically. While there is parity in the ratio of female to male medical students in the US, and females are as competitive as males for NIH grant funding, fewer female physician-scientists comprise the workforce: within the workforce, females submit fewer NIH grant applications than their male colleagues $(7,9)$.

The lack of research dollars dedicated to understanding the pathophysiology and treatment of psychiatric disorders is a barrier not only to making significant medical advances for our patients but also to developing the physician-scientist workforce to fuel those advances. The $\mathrm{NIH}$ has made tremendous efforts to improve growth and retention of this diminishing workforce. The recent Physician-Scientist Workforce Working Group has set forth recommendations on how the NIH can continue its development and support of this vital resource(9) by addressing remaining challenges. However, the challenges for physicianscientists establishing and then sustaining a productive clinical research career should be cooperatively addressed by all stakeholders (e.g. government, academia, private companies, etc.) who benefit from the medical advances fueled by research dollars.

As a psychiatrist and psychopharmacologist, I provide care for perinatal women with depression and anxiety disorders. The limitations of our field's current understanding of the pathophysiology and treatment (or prevention) of these disorders, drives me as a physicianscientist to conduct clinical and translational research aimed at improving care for these depressed mothers and their at-risk children. Noble intentions and outstanding science are not sufficient however, to maintaining research funding in this funding climate. In pursuit of my mission to improve patient care through translational research, I utilized research training programs from the NIH since medical school. My research has been made possible 
through essential NIH, foundation and institutional funding mechanisms aimed at supporting research by physician-scientists. Without future research support, our lab's advances in unraveling the pathophysiology of perinatal depression and developing novel therapeutics for depressed mothers will be halted.

\section{Acknowledgments}

Funding Sources

This work was supported by NIH Grant (5K23MH097794) and NIH L30MH104713-01 awarded to K.M.D.

\section{References}

1. LEY TJ, ROSENBERG LE. The physician-scientist career pipeline in 2005: build it, and they will come. The Journal of the American Medical Association (JAMA). 2005; 294:1343-51.

2. WYNGAARDEN JB. The clinical investigator as an endangered species. The New England Journal of Medicine. 1979; 301:1254-9. [PubMed: 503128]

3. National Research Council. Careers in Clinical Research: Obstacles and Opportunities. Washington, DC: The National Academies Press; 1994. Available at http://www.nap.edu/catalog/2142/careersin-clinical-research-obstacles-and-opportunities

4. Association of American Medical Colleges, American Medical Association, Wake Forest University School of Medicine. Clinical Research: A National Call To Action. Washington, DC: 1999. Available at https://www.aamc.org/publications

5. NATHAN DG. Clinical research: perceptions, reality, and proposed solutions. National Institutes of Health Director's Panel on Clinical Research. The Journal of the American Medical Association (JAMA). 1998; 280:1427-31.

6. TEO AR. The development of clinical research training: past history and current trends in the United States. Academic medicine : Journal of the Association of American Medical Colleges. 2009; 84:433-8. [PubMed: 19318772]

7. INSEL, T. The Anatomy of NIMH Funding. [cited 2015 April 6]. Available from: http:// www.nimh.nih.gov/funding/funding-strategy-for-research-grants/white-paper_149362.pdf

8. Occupational Employment and Wages. Psychiatrists: United States Department of Labor and Bureau of Labor Statistics. May 2014. [cited 2015 April 6]. Available from: http:// www.bls.gov/oes/current/oes291066.htm

9. Advisory Committee to the Director Physician-Scientist Workforce Working Group Report 2014. Bethesda, MD: The NIH Physician-Scientist Workforce Workgroup; [cited 2015 April 6]. Available from: http://report.nih.gov/workforce/psw/psw-group.aspx 